\section{The author replies below}

Martin draws inferences from my article which the text does not justify. Electricity has been shown over a $\mathbf{1 0 0}$ years or more to be $a$, basically, very safe source of power and if it does have any long-term effects then they are surely of low significance compared with its overall benefits. If the long-term effects, if any, are the major issue which Martin suggests, why have we not seen more evidence of them as the use of electricity has expanded and grown?

I most certainly do not discount the results of the work of Drs Adey, Goodman or Leal, but the public and the press, unfortunately, pay much regard to the work of other investigators which is not even published in scientific journals and much of which does not stand up to critical scientific analysis.

In spite of Martin's assertions that 'science experiments have utilized field strengths in the range that one might encounter in our everyday environment (0.01-30 mT)' (quoted from Duchene, Health Physics $1990 ; 58: 113-22)$, few if any experiments have used the very weak fields $(0.2-0.3 \mathrm{mT})$ which epidemiological studies have linked with cancer. The same author in the same publication states 'Although some epidemiological studies suggest an association between exposure to $50 / 60 \mathrm{~Hz}$ fields and cancer, others do not. Not only is this association not proven, but present data do not provide any basis for health risk assessment useful for the development of exposure limits. Current laboratory studies are testing the hypothesis that $50 / 60 \mathrm{~Hz}$ fields may act as, or with, a cancer promoter. These studies are still exploratory in nature and have not established any human health risk from exposure to these fields'.

R A F Cox

Chief Medical Officer National Power plc, Sudbury House 15 Newgate Street, London EC1A 7AU

The editorial by Cox (February 1990 JRSM, p 63) contains errors of commission and omission, leading to a skewed picture of health hazard from non-ionising electromagnetic irradiation.

The public is increasingly aware of such hazards simply by living under or near power lines: unprompted complaints from hapless residents, who have no idea of the scientific literature, let alone media reports, consistently reveal the same cocktail of symptoms, including depression, suicide, immune deficit, lymphocytic/lymphoblastic leukaemia, hyperactivity, and sudden unexplained death in infancy.

A number of well-controlled studies round the world support these findings ${ }^{1-4}$, summarized in a dozen or so textbooks, the latest of which ${ }^{5}$ points out that: in the ELF power frequency range vigorous research is now being sponsored by the US Dept of Energy, and the Electric Power Research Institute as well as a few states in the US Active research programmes are also to be found in Canada, Sweden, England, Italy, and the USSR and smaller programmes are being developed in various other countries'.

In the UK, Dr Stephen Perry has identified correlations between powerlines and suicide ${ }^{6}$, Dr David Dowson between powerlines and depression and headache ${ }^{7}$, and whilst recent findings by Dr Gardner at Southampton link childhood leukaemia to nuclear power station workers ${ }^{8}$, it is indisputable that power lines also emerge from such installations. My own observations consistently find a correlation between high electric fields in residences and sudden unexplained infant death'.

Ahlbohm's 1988 study which Dr Cox cites has since been superseded by the US Congress Office of Technology Assessment report of June $1989^{10}$, which concludes:

'Although as recently as a few years ago scientists stated that available evidence showed no health risks from power frequency fields, emerging evidence no longer allows a categorical denial that risks exist'.

It is noticeable that $\mathrm{Dr}$ Cox omits any reference to research later than 1988.

It took 30 years before the hazards of electromagnetic $\mathrm{X}$-radiation were formally recognized, and the history of medical practice since then has been one of continual downward revisions of permitted exposure limits.

Since X-rays and domestic electric power are both part of the same electromagnetic energy continuum, the sensible course, as Baruch Modan points out ${ }^{11}$, would be to regard high EM fields as hazardous until proved otherwise, and not the other way around. ROGER COGHIII

Postgraduate Research Student in electromagnetism and the immune system Occupational Health Department University of Surrey

\section{References}

1 Smith CW, Baker RD. Comments on the paper 'Environmental power frequency electromagnetic fields and suicide', Health Phys 1982;43:439-41

2 Perry FS, Pearl L. Health effects of ELF fields and illness in multistorey blocks. Public Health 1988;102: 11-18

3 Tomenius L. Electrical constructions and $50 \mathrm{~Hz}$ magnetic fields at the dwellings of tumour cases (0-18 years) in the county of Stockholm. International Symposium, Prague, 1982

4 Eckert E. Plotzlicher und unerwarteter Tod in Kleinskindesalter und elektromagnetische Felder. Med Klin 1976;71:1500-5

5 Wilson BW, Stevens RG, et al. Extremely low frequency EM fields: the question of cancer. Ohio: Battelle Press, 1990

6 Perry FS, Reichmanis M, et al. Environmental power frequency magnetic fields and suicide. Health Phys 1981;41:267-77

7 Dowson D, Lewith GT, et al. Overhead high voltage cables and recurrent headache and depressions. Practitioner 1988;232:435-6

8 Gardner MJ, Snee MP, et al. Results of case-control study of leukaemia and lymphoma among young people near Sellafield nuclear plant in W. Cumbria. BMJ 1990; 300:423-34

9 Coghill RW. The electric railway children: an electromagnetic aetiology for cot death? Hosp Equipment Supplies June 1989:9

10 U.S. Congress Office of Technology Assessment. Biological effects of power frequency electric and magnetic fields. Background paper OTA BP-E-53, Washington DC, May 1989

11 Modan B. Exposure to electromagnetic fields and brain malignancy: a newly discovered menace? Am J Ind Med 1988;13:625-7

\section{The author replies below:}

Unfortunately, the literature on the subject of the health effects of electric and magnetic fields is full of anecdotal, unsubstantiated, inaccurate and scientifically dubious references and Mr Coghill's catalogue of alleged effects does nothing to improve this.

To take two examples: Dr Gardner's study was not on nuclear power station workers. It was on children 